\title{
THE DEGREE-DIAMETER PROBLEM FOR OUTERPLANAR GRAPHS
}

\author{
Peter DANKELMANN \\ Department of Mathematics \\ University of Johannesburg \\ Johannesburg, South Africa \\ e-mail: pdankelmann@uj.ac.za \\ ELIZABETH JONCK \\ School of Mathematics \\ University of the Witwatersrand \\ Johannesburg, South Africa \\ e-mail: Betsie.Jonck@wits.ac.za \\ AND \\ TOMÁŠ VETRÍK \\ Department of Mathematics and Applied Mathematics \\ University of the Free State \\ Bloemfontein, South Africa \\ e-mail: vetrikt@ufs.ac.za
}

\begin{abstract}
For positive integers $\Delta$ and $D$ we define $n_{\Delta, D}$ to be the largest number of vertices in an outerplanar graph of given maximum degree $\Delta$ and diameter $D$. We prove that $n_{\Delta, D}=\Delta^{\frac{D}{2}}+O\left(\Delta^{\frac{D}{2}-1}\right)$ if $D$ is even, and $n_{\Delta, D}=3 \Delta^{\frac{D-1}{2}}+O\left(\Delta^{\frac{D-1}{2}-1}\right)$ if $D$ is odd. We then extend our result to maximal outerplanar graphs by showing that the maximum number of vertices in a maximal outerplanar graph of maximum degree $\Delta$ and diameter $D$ asymptotically equals $n_{\Delta, D}$.
\end{abstract}

Keywords: outerplanar, diameter, degree, degree-diameter problem, distance, separator theorem.

2010 Mathematics Subject Classification: 05C35, 05C12. 


\section{REFERENCES}

[1] M. Abas, Cayley graphs of diameter two and any degree with order half of the Moore bound, Discrete Appl. Math. 173 (2014) 1-7.

doi:10.1016/j.dam.2014.04.005

[2] C. Balbuena, M. Miller, J. Širáň and M. Ždímalová, Large vertex-transitive graphs of diameter 2 from incidence graphs of biaffine planes, Discrete Math. 313 (2013) 2014-2019. doi:10.1016/j.disc.2013.03.007

[3] C. Dalfó, C. Huemer and J. Salas, The degree/diameter problem in maximal planar bipartite graphs, Electron. J. Combin. 23 (1) (2016) \#P60.

[4] P. Dankelmann, D. Erwin, W.D. Goddard, S. Mukwembi and H.C. Swart, A characterisation of eccentric sequences of maximal outerplanar graphs, Australas. J. Combin. 58 (2014) 376-391.

[5] P. Dankelmann and T. Vetrík, The degree-diameter problem for claw-free graphs and hypergraphs, J. Graph Theory 75 (2014) 105-123. doi:10.1002/jgt.21716

[6] A.M. Farley and A. Proskurowski, Computation of the center and diameter of outerplanar graphs, Discrete Appl. Math. 2 (1980) 185-191. doi:10.1016/0166-218X(80)90039-6

[7] M. Fellows, P. Hell and K. Seyffarth, Large planar graphs with given diameter and maximum degree, Discrete Appl. Math 61 (1995) 133-153. doi:10.1016/0166-218X(94)00011-2

[8] R. Feria-Purón and G. Pineda-Villavicencio, On bipartite graphs of defect at most 4, Discrete Appl. Math 160 (2012) 140-154. doi:10.1016/j.dam.2011.09.002

[9] P. Hell and K. Seyffarth, Largest planar graphs of diameter two and fixed maximum degree, Discrete Math. 111 (1993) 313-322. doi:10.1016/0012-365X(93)90166-Q

[10] R.J. Lipton and R.E. Tarjan, A separator theorem for planar graphs, SIAM J. Appl. Math. 36 (1979) 177-189. doi: $10.1137 / 0136016$

[11] E. Nevo, G. Pineda-Villavicencio and D.R. Wood, On the maximum order of graphs embedded in surfaces, J. Combin. Theory Ser. B 119 (2016) 28-41. doi:10.1016/j.jctb.2015.12.004

[12] A. Proskurowski, Centers of maximal outerplanar graphs, J. Graph Theory 4 (1980) 75-79. doi:10.1002/jgt.3190040108

[13] K. Seyffarth, Maximal planar graphs of diameter two, J. Graph Theory 13 (1989) 619-648. doi:10.1002/jgt.3190130512 
[14] S.A. Tishchenko, Maximum size of a planar graph with given degree and even diameter, European J. Combin. 33 (2012) 380-396.

doi:10.1016/j.ejc.2011.09.005

[15] T. Vetrík, Abelian Cayley graphs of given degree and diameter 2 and 3, Graphs Combin. 30 (2014) 1587-1591.

doi:10.1007/s00373-013-1361-5

[16] T. Vetrík, R. Simanjuntak and E. Baskoro, Large bipartite Cayley graphs of given degree and diameter, Discrete Math. 311 (2011) 324-326.

doi:10.1016/j.disc.2010.10.015

[17] Y. Yang, J. Lin and Y. Dai, Largest planar graphs and largest maximal planar graphs of diameter two, J. Comput. Appl. Math. 144 (2002) 349-358.

doi:10.1016/S0377-0427(01)00572-6

Received 8 January 2016

Revised 5 August 2016

Accepted 5 August 2016 